\title{
Electron attachment properties of c-C4F8O in different environments
}

\section{Journal Article}

Author(s):

Chachereau, Alise (D); Fedor, Juraj; Janečková, Radmila; Kočišek, Jaroslav; Rabie, Mohamed; Franck, Christian (D)

Publication date:

2016-09-21

Permanent link:

https://doi.org/10.3929/ethz-b-000121268

Rights / license:

In Copyright - Non-Commercial Use Permitted

Originally published in:

Journal of Physics D: Applied Physics 49(37), https://doi.org/10.1088/0022-3727/49/37/375201 


\section{This is a post-refereeing copy of the manuscript submitted to IOP.}

The original version can be found on the IOP web-page:

Digital Object Identifier: doi.org/10.1088/0022-3727/49/37/375201 


\title{
Electron attachment properties of $\mathrm{c}-\mathrm{C}_{4} \mathrm{~F}_{8} \mathrm{O}$ in different environments
}

\author{
A. Chachereau ${ }^{1}$, J. Fedor ${ }^{2}$, R. Janečková ${ }^{3,4}$, J. Kočišek $^{2}$, M. \\ Rabie $^{1}$, C. M. Franck ${ }^{1}$ \\ ${ }^{1}$ Power Systems and High Voltage Laboratories, ETH Zurich, CH-8092 Zurich, \\ Switzerland \\ 2 J. Heyrovský Institute of Physical Chemistry, Czech Academy of Sciences, \\ Dolejškova 3, CZ-18223 Prague, Czech Republic \\ ${ }^{3}$ Department of Chemistry, University of Fribourg, Chemin du Musée 9, CH-1700 \\ Fribourg, Switzerland \\ ${ }^{4}$ Faculty of Safety Engineering, VŠB - Technical University of Ostrava, Lumírova 13, \\ CZ-70030, Ostrava 3 - Výškovice, Czech Republic \\ E-mail: alisec@ethz.ch (A. Chachereau) and juraj.fedor@jh-inst.cas.cz (J. \\ Fedor)
}

\begin{abstract}
The electron attachment properties of octafluorotetrahydrofuran $\left(\mathrm{c}-\mathrm{C}_{4} \mathrm{~F}_{8} \mathrm{O}\right)$ are investigated using two complementary experimental setups. The attachment and ionization cross sections of $\mathrm{c}-\mathrm{C}_{4} \mathrm{~F}_{8} \mathrm{O}$ are measured using an electron beam experiment. The effective ionization rate coefficient, electron drift velocity and electron diffusion coefficient in $\mathrm{c}_{-} \mathrm{C}_{4} \mathrm{~F}_{8} \mathrm{O}$ diluted to concentrations lower than $0.6 \%$ in the buffer gases $\mathrm{N}_{2}, \mathrm{CO}_{2}$ and $\mathrm{Ar}$, are measured using a pulsed Townsend experiment. A kinetic model is proposed, which combines the results of the two experiments.
\end{abstract}

PACS numbers: $00.00,20.00,42.10$

Keywords: $\mathrm{c}-\mathrm{C}_{4} \mathrm{~F}_{8} \mathrm{O}$, octafluorotetrahydrofuran, swarm parameters, electron attachment, three-body attachment.

Submitted to: J. Phys. D: Appl. Phys.

\section{Introduction}

Octafluorotetrahydrofuran $\left(\mathrm{c}-\mathrm{C}_{4} \mathrm{~F}_{8} \mathrm{O}\right)$ is considered for use as a radiating medium in Cherenkov detectors [1] and as a cleaning agent for chemical vapor deposition chambers to replace plasma processing gases with high global warming potential (GWP) [2]. The GWP of $\mathrm{c}_{-} \mathrm{C}_{4} \mathrm{~F}_{8} \mathrm{O}$ is about 8'000 [2]. It could also be considered as an alternative to sulphur hexafluoride $\left(\mathrm{SF}_{6}\right)$ in high voltage gaseous insulation. $\mathrm{SF}_{6}$ has a high dielectric strength, low boiling point and chemical stability, but it has a GWP of 23'500 [3]. 
Therefore, it could be advantageously replaced by diluted mixtures of $\mathrm{c}_{-} \mathrm{C}_{4} \mathrm{~F}_{8} \mathrm{O}$ with one or more buffer gases, such as $\mathrm{N}_{2}$ or $\mathrm{CO}_{2}$.

Electron swarm parameters such as the effective ionization rate, the electron drift velocity and the electron diffusion coefficient are useful for modeling low temperature plasmas in general $[4,5]$, and in particular for modelling non-thermal gas discharges and assessing the performance of an electronegative gas for high voltage insulation $[6,7]$. It is common practice to calculate the effective ionization rate by solving the electron Boltzmann equation [8], or by means of Monte-Carlo simulations [9, 10]. The required electron scattering cross sections can be obtained for instance by means of electron beam experiments [11]. However, the ion kinetic processes are often neglected in such models, since it would require considerable effort to determine the scattering cross sections of ions and to calculate the transport properties of both electrons and ions. This is problematic in some electronegative gases where electron attachment proceeds through the formation of an unstable parent anion, and the collisions of this anion with neutrals are crucial for the electron attachment rate $[12,13]$. Another approach is to measure the effective ionization rate in a swarm experiment [14]. The effective ionization rate coefficient resulting from all kinetic processes is obtained, but less information is gained on the kinetic scheme itself. Therefore, the two approaches are complementary. Finally, since both beam and swarm experiments are performed in specific conditions, typically at low gas pressures, and for a limited number of gas mixtures, kinetic models are necessary to extend this data to other conditions, such as the high gas pressures of several bar used in high voltage insulation equipment.

In the present work, the properties of $\mathrm{c}_{-} \mathrm{C}_{4} \mathrm{~F}_{8} \mathrm{O}$ are investigated in two different environments: pure $\mathrm{c}_{-} \mathrm{C}_{4} \mathrm{~F}_{8} \mathrm{O}$ at low gas pressure in an electron beam experiment, and diluted mixtures of $\mathrm{c}_{-} \mathrm{C}_{4} \mathrm{~F}_{8} \mathrm{O}$ in $\mathrm{N}_{2}, \mathrm{CO}_{2}$ and $\mathrm{Ar}$ at intermediate gas pressure in a swarm experiment. The results are combined to propose a model for electron attachment to $\mathrm{c}-\mathrm{C}_{4} \mathrm{~F}_{8} \mathrm{O}$. The structure of this work is shown in figure 1 . In section 1 , the attachment cross sections and the total ionization cross section of $\mathrm{c}_{-} \mathrm{C}_{4} \mathrm{~F}_{8} \mathrm{O}$ are obtained using an electron beam experiment. In section 2, the electron Boltzmann equation is solved in the buffer gases $\mathrm{N}_{2}, \mathrm{CO}_{2}$ and Ar to obtain the electron energy distribution function, the electron drift velocity and the effective ionization rate. It is discussed how the attachment and ionization processes in $\mathrm{c}_{-} \mathrm{C}_{4} \mathrm{~F}_{8} \mathrm{O}$ identified in the beam experiment can be used for calculating the effective ionization rate in $\mathrm{c}^{-} \mathrm{C}_{4} \mathrm{~F}_{8} \mathrm{O}$ mixtures with $\mathrm{N}_{2}, \mathrm{CO}_{2}$ and Ar. Then, the effective ionization rate is calculated in the mixtures of $0.5 \% \mathrm{c}_{-} \mathrm{C}_{4} \mathrm{~F}_{8} \mathrm{O}$ in $\mathrm{CO}_{2}, 0.6 \% \quad \mathrm{c}_{4} \mathrm{C}_{8} \mathrm{O}$ in $\mathrm{N}_{2}$ and $0.1 \% \quad \mathrm{c}_{-} \mathrm{C}_{4} \mathrm{~F}_{8} \mathrm{O}$ in $\mathrm{Ar}$. In section 3, the electron swarm parameters are measured in $\mathrm{N}_{2}, \mathrm{CO}_{2}$ and $\mathrm{Ar}$ and in the aforementioned mixtures with $\mathrm{c}-\mathrm{C}_{4} \mathrm{~F}_{8} \mathrm{O}$, at different gas pressures, using a pulsed Townsend experiment. Swarm parameters measurements in similar mixtures were presented in a previous work [15], however, these measurements were limited to a narrower pressure range and the pressure dependence of results was not investigated. As the results from sections 2 and 3 are found to be conflicting, a three-body attachment mechanism is proposed in section 4 to complete the electron kinetics scheme described in section 2. This model is consistent 


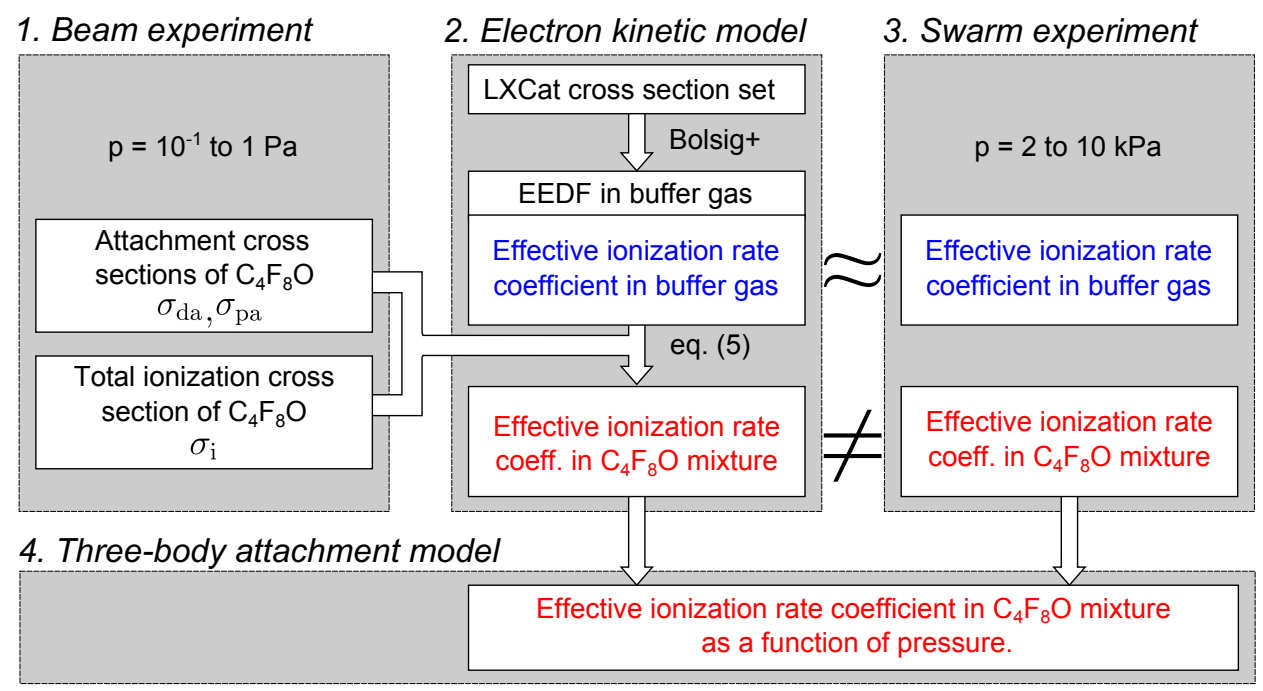

Figure 1: Structure of the paper and overview of the measurements and calculations. 'EEDF' stands for electron energy distribution function, 'p' stands for gas pressure.

with the two experiments, and useful for extending the present data to arbitrary gas pressures and small concentrations of $\mathrm{c}_{-} \mathrm{C}_{4} \mathrm{~F}_{8} \mathrm{O}$.

\section{Beam experiment}

\subsection{Experimental setup}

In the first experimental setup - a quantitative dissociative electron attachment (DEA) spectrometer $[16,17]$ - the electron beam passes a stagnant gas target of $\mathrm{c}_{-} \mathrm{C}_{4} \mathrm{~F}_{8} \mathrm{O}$ at single-collision conditions. The electrons emitted from a hot filament are selected according to their kinetic energy in a trochoidal electron monochromator. They are then accelerated to desired energy and pass through the collision chamber filled with the studied gas. The electron current is monitored by a Faraday cup located behind the collision cell.

The entire experiment is pulsed: the electrons pass the target chamber during $200 \mathrm{~ns}$ while it is field-free and after additional $200 \mathrm{~ns}$ (when the electrons leave the chamber) a negative voltage of $-300 \mathrm{~V}$ is pulsed across the chamber which pushes the anions formed in the cell towards the ion time-of-flight (TOF) mass analyzer in the direction perpendicular to the electron beam. The anions are detected with a microchannel plate, counted, and their arrival times are analyzed. The time between anion production and their detection is in the order of microseconds, namely $7.6 \mu$ s for the heaviest anion in the present measurements. The experiment is repeated with $50 \mathrm{kHz}$ frequency. The spectra are stored as two-dimensional maps - ion count as a function of electron energy and of arrival time. This allows the extraction of both negative ion mass spectra and ion-yield versus electron-energy for each anion.

The electron-energy scale is calibrated using the onset of $\mathrm{O}^{-}$signal from $\mathrm{CO}_{2}$ at 
$3.99 \mathrm{eV}$. The shape of the $\mathrm{O}^{-}$peak is also used to determine the energy resolution of the electron beam as described in [18]. The absolute cross sections are calibrated using two independent reference values: the $\mathrm{O}^{-}$from $\mathrm{CO}_{2}[19]$ and $\mathrm{HCOO}^{-}$from $\mathrm{HCOOH}$ [20]. The uncertainty of the obtained cross sections is $\pm 20 \%$ (two standard deviations). It is obtained as a combination or the error of the present relative measurements $( \pm 15 \%)$ and of the error of the absolute cross sections used for normalization. The latter is taken as $\pm 15 \%$ in view of the results from various groups listed in [20].

The electron-beam resolution in the current experiment is approximately $200 \mathrm{meV}$. As seen from test measurements with a small impurity of $\mathrm{SF}_{6}$, the electrons down to the energy of approximately $100 \mathrm{meV}$ are present in the beam. The pressure in the cell is monitored with a capacitance manometer and is varied from $1 \times 10^{-2}$ to $1 \times 10^{-1} \mathrm{~Pa}$. This range of pressures ensures single-collision conditions between electrons and the gas molecules, and ensures that the collision probability of created anions with other molecules is negligible on timescale of the anion extraction.

Additionally to electron attachment cross sections, both dissociative and nondissociative, the total positive ionization cross section has also been measured. For the purpose of this measurement, the setup was used in the total ion collection mode [19]. Here the monochromator is not pulsed and the total analogue ion current (in the order of picoamperes) is measured on the molybdenum electrode placed in the collision chamber. This is the same electrode that serves as a pusher in the pulsed mode. For the sake of the continuous wave measurements, it is connected to a picoampermeter. The ion current is recorded as a function of electron energy. The cross section is then calibrated by recording the ion current for argon which has known positive ionization cross section [21].

\subsection{Ionization and attachment cross sections of $c-C_{4} F_{8} O$ at single-collision conditions}

Upon electron impact in the electron energy range up to $6 \mathrm{eV}$, the $\mathrm{c}_{-} \mathrm{C}_{4} \mathrm{~F}_{8} \mathrm{O}$ molecule exhibits a rich fragmentation pattern. Figure 2 (a) shows the negative ion mass spectrum recorded at the electron energy of $2 \mathrm{eV}$. A number of anionic fragments can be seen, which is expected for a molecular system of this size [18]. What is not expected, is the observation of the parent anion $\mathrm{C}_{4} \mathrm{~F}_{8} \mathrm{O}^{-}$. At single collision conditions, the process of electron attachment basically always proceeds via formation of the transient anion, also called a resonance, in this case $\left(\mathrm{C}_{4} \mathrm{~F}_{8} \mathrm{O}^{-}\right)^{*}$. The transient anion has an excess of internal energy which is released either by autodetachment of the electron on the timescale of typically femto- to picoseconds, or by anion's dissociation on the same timescale which leads to stable anionic fragments. In present case, however, some transient negative ions survive up to $7.6 \mu \mathrm{s}$, which is their detection time in the time-of-flight spectrometer.

Figure 2 (b) shows the total dissociative electron attachment cross section $\sigma_{\mathrm{da}}$ (sum of partial cross sections for all the anionic fragments) and the cross section $\sigma_{\mathrm{pa}}$ for the production of the parent anion $\left(\mathrm{C}_{4} \mathrm{~F}_{8} \mathrm{O}^{-}\right)_{\mathrm{L}}^{*}$ (" $\mathrm{L}$ " is standing for long-lived). The electron attachment cross sections show three peaks (one peak in $\sigma_{\mathrm{pa}}$ and two peaks in $\left.\sigma_{\mathrm{da}}\right)$ which correspond to elementary attachment processes mediated by the formation 
of different types of transient anions. The peaks are positioned at $0.9,1.8$ and $3.4 \mathrm{eV}$. The first peak at $0.9 \mathrm{eV}$ corresponds to the production of the long-lived parent anion $\left(\mathrm{C}_{4} \mathrm{~F}_{8} \mathrm{O}^{-}\right)_{\mathrm{L}}^{*}$. It is produced at energies considerably higher than thermal, which is rare. Most of the known long-lived parent anions created in binary collisions with an electron are formed at energies close to $0 \mathrm{eV}$, e.g., $\mathrm{SF}_{6}^{-}$or $\mathrm{CCl}_{4}^{-}$. The stabilization mechanism of the $\left(\mathrm{C}_{4} \mathrm{~F}_{8} \mathrm{O}^{-}\right)_{\mathrm{L}}^{*}$ on the microsecond time scale and its fragmentation pathways will be discussed in a separate publication [22]. The second and third peaks at 1.8 and $3.4 \mathrm{eV}$ correspond to dissociative attachment processes.

In order to ensure that three-body mechanisms do not play a role in the beam experiment, a range of control measurements was performed. All ion yields - both of the fragmented anions and of the parent anion $\left(\mathrm{C}_{4} \mathrm{~F}_{8} \mathrm{O}^{-}\right)_{\mathrm{L}}^{*}-$ were found to be linearly dependent on the target gas pressure. Also, all signals were linearly dependent on the electron current passing the collision cell.

Figure 3 shows the total positive ionization cross section $\sigma_{\mathrm{i}}$ of $\mathrm{c}-\mathrm{C}_{4} \mathrm{~F}_{8} \mathrm{O}$. Since the positive cross section is measured with the setup operated in the total ion collection mode, the partial cross sections are not available. This cross section was measured to provide an input for calculations of section 2 , where only the total ionization cross section is needed. The ionization energy is $11.8 \mathrm{eV}$. It was determined by fitting the measured data by a Wannier-like threshold law [23, 24].

(a)

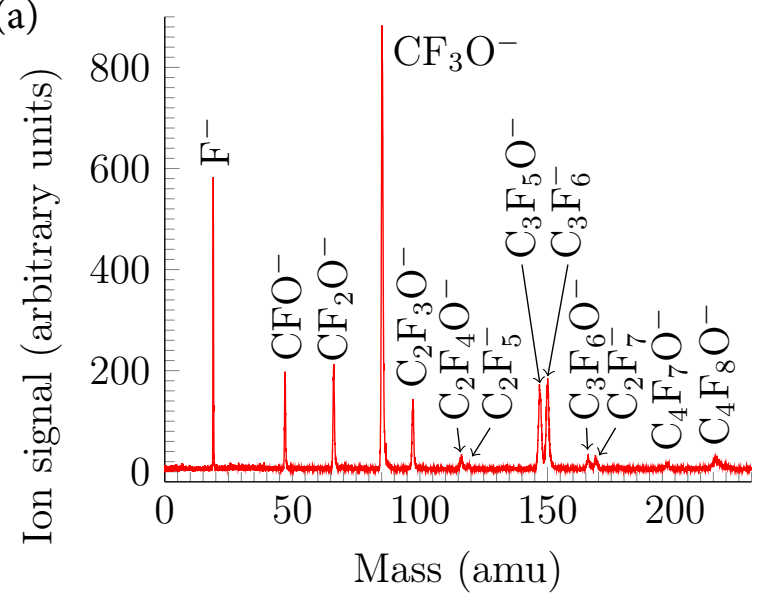

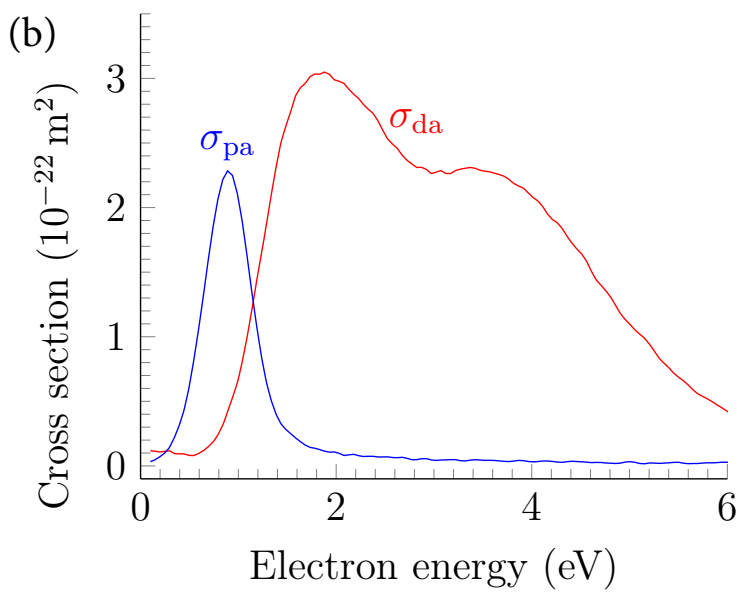

Figure 2: (a) Negative ion mass spectrum in the beam experiment recorded at an electron energy of $2 \mathrm{eV}$. (b) Total dissociative electron attachment cross section $\sigma_{\text {da }}$ (sum of the partial cross sections for all the anionic fragments shown in (a)), and parent anion attachment cross section $\sigma_{\mathrm{pa}}$. 


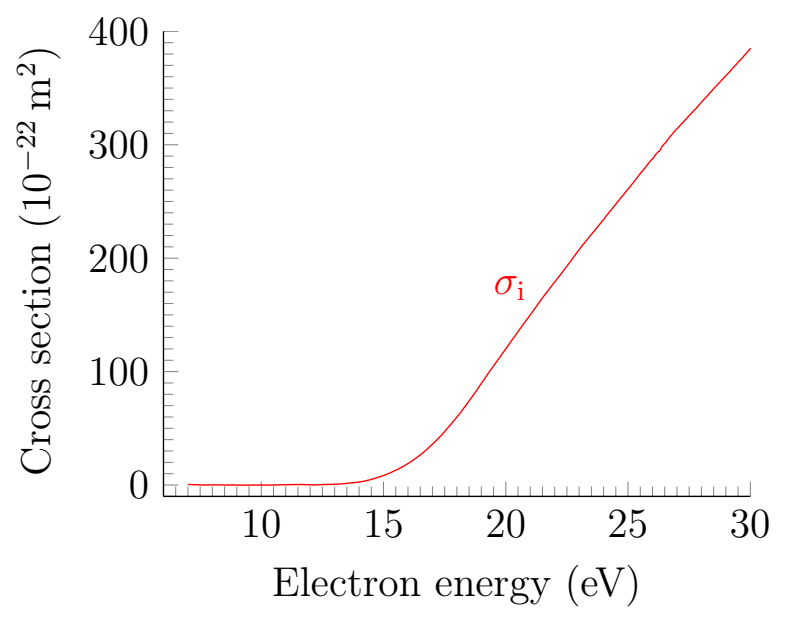

Figure 3: Total positive ionization cross section of $c-\mathrm{C}_{4} \mathrm{~F}_{8} \mathrm{O}$.

\section{Electron kinetic model}

In section 1 , the total ionization and dissociative attachment cross sections, $\sigma_{\mathrm{i}}$ and $\sigma_{\mathrm{da}}$ were obtained, as well as the long-lived parent anion attachment cross section $\sigma_{\mathrm{pa}}$. These scattering cross sections correspond to the kinetic processes (1-3)

$$
\begin{aligned}
& \mathrm{C}_{4} \mathrm{~F}_{8} \mathrm{O}+e \stackrel{k_{\mathrm{i}}}{\rightarrow} 2 \mathrm{e}+\mathrm{A}^{+}(+\mathrm{B}) \text { (all ionization processes), } \\
& \mathrm{C}_{4} \mathrm{~F}_{8} \mathrm{O}+e \stackrel{k_{\mathrm{da}}}{\rightarrow} \mathrm{D}^{-}+\mathrm{E} \text { (all dissociative attachment processes), } \\
& \mathrm{C}_{4} \mathrm{~F}_{8} \mathrm{O}+e \stackrel{k_{\mathrm{pa}}}{\rightarrow}\left(\mathrm{C}_{4} \mathrm{~F}_{8} \mathrm{O}^{-}\right)_{\mathrm{L}}^{*} \text { (parent ion attachment, long-lived). }
\end{aligned}
$$

In the above kinetic scheme, $k_{\mathrm{i}}, k_{\mathrm{da}}$ and $k_{\mathrm{pa}}$ are the reaction rate coefficients for the processes of ionization, dissociative attachment, and long-lived parent ion formation. The rate coefficient $k$ can be calculated from the corresponding scattering cross section $\sigma$ as follows

$$
k=\sqrt{\frac{2}{m_{\mathrm{e}}}} \int_{0}^{\infty} \sigma \varepsilon f(E / N, \varepsilon) \mathrm{d} \varepsilon
$$

where $m_{\mathrm{e}}$ is the electron mass and $f(E / N, \varepsilon)$ is electron energy distribution function (EEDF) in the gas or gas mixture. The EEDF is obtained by solving the Boltzmann equation for electrons, which requires the input of the electron scattering cross sections for all the considered gases. Full cross section sets are available for $\mathrm{N}_{2}, \mathrm{CO}_{2}$ and $\mathrm{Ar}$, for instance on the LXcat database [5, 25]. In this work, the cross section set from Biagi [26] is used for $\mathrm{N}_{2}$, Phelps [27] for $\mathrm{CO}_{2}$, and SIGLO [28] for Ar. A set of electron scattering cross sections for $\mathrm{c}_{-} \mathrm{C}_{4} \mathrm{~F}_{8} \mathrm{O}$ is presently not available. However, it can be assumed that the EEDF in the buffer gas is not changed when a small amount of $\mathrm{c}-\mathrm{C}_{4} \mathrm{~F}_{8} \mathrm{O}$ is added $[29,30]$. Therefore, the rate coefficients $k_{\mathrm{i}}, k_{\mathrm{da}}$ and $k_{\mathrm{pa}}$ in the diluted $\mathrm{c}-\mathrm{C}_{4} \mathrm{~F}_{8} \mathrm{O}$ mixtures can be calculated using equation (4) and taking the EEDF calculated for the buffer gas. 
The electron Boltzmann equation is solved using the solver Bolsig $+[8]$, which makes use of the two-term approximation, to obtain the EEDF, the effective ionization rate coefficient $k_{\text {eff }}^{\mathrm{b}}$, the electron drift velocity $w^{\mathrm{b}}$ and the longitudinal electron diffusion coefficient $N D_{\mathrm{L}}^{\mathrm{b}}$ in the buffer gases $\mathrm{N}_{2}, \mathrm{CO}_{2}$ and Ar. The present calculations are performed at relatively low density reduced electric field $E / N$ ( $E$ is the electric field and $N$ is the gas number density). In this range of $E / N$, the two-term approximation yields precise results, as was shown for instance in $\mathrm{N}_{2}$ [31] and $\mathrm{Ar}$ [32].

The effective ionization rate coefficient $k_{\text {eff }}^{0}$ (the exponent 0 is used later on in section 4 to signify "limit at low pressure") in a diluted mixture of c- $\mathrm{C}_{4} \mathrm{~F}_{8} \mathrm{O}$ with $\mathrm{N}_{2}$, $\mathrm{CO}_{2}$ or Ar can obtained as

$$
k_{\mathrm{eff}}^{0}=(1-r) k_{\mathrm{eff}}^{\mathrm{b}}+r\left(k_{\mathrm{i}}-k_{\mathrm{da}}-k_{\mathrm{pa}}\right),
$$

where $r$ is the ratio of $\mathrm{c}_{-} \mathrm{C}_{4} \mathrm{~F}_{8} \mathrm{O}$ in the mixture.

In this model - processes (1-3) - electron detachment from $\left(\mathrm{C}_{4} \mathrm{~F}_{8} \mathrm{O}^{-}\right)_{\mathrm{L}}^{*}$ is neglected. Autodetachment from $\left(\mathrm{C}_{4} \mathrm{~F}_{8} \mathrm{O}^{-}\right)_{\mathrm{L}}^{*}$ is indeed negligible on the timescale of the swarm experiment since the lifetime of $\left(\mathrm{C}_{4} \mathrm{~F}_{8} \mathrm{O}^{-}\right)_{\mathrm{L}}^{*}$ was found to be at least microseconds, but there is the possibility for collisional detachment in the swarm experiment. Therefore, the electron attachment via process (3) is possibly overestimated.

Using equation (5), $k_{\text {eff }}^{0}$ is calculated in the mixtures of $0.6 \% \mathrm{c}_{-} \mathrm{C}_{4} \mathrm{~F}_{8} \mathrm{O}$ in $\mathrm{N}_{2}, 0.5 \%$ $\mathrm{c}_{-} \mathrm{C}_{4} \mathrm{~F}_{8} \mathrm{O}$ in $\mathrm{CO}_{2}$ and $0.1 \% \mathrm{c}_{-} \mathrm{C}_{4} \mathrm{~F}_{8} \mathrm{O}$ in Ar. The calculated values of $k_{\text {eff }}^{\mathrm{b}}, w^{\mathrm{b}}$ and $N D_{\mathrm{L}}^{\mathrm{b}}$ in the gases $\mathrm{N}_{2}, \mathrm{CO}_{2}$ and $\mathrm{Ar}$ and of $k_{\text {eff }}^{0}$ in the corresponding gas mixtures are shown in figures 7,8 and 9, respectively, and compared to the same quantities measured in the swarm experiment.

\section{Swarm experiment}

\subsection{Experimental setup and methods}

The swarm parameter measurements were performed with the automated Pulsed Townsend (PT) setup described in [33]. The experimental setup allows for varying the electrode gap distance, the voltage and the gas pressure. The measurements are performed at room temperature, which is monitored. About $10^{7}$ electrons are released in the gas vessel from a $12 \mathrm{~nm}$ thick palladium photocathode, which is back illuminated by a $266 \mathrm{~nm}$ laser. The laser pulses have a duration of $1.5 \mathrm{~ns}$ FWHM and a $20 \mathrm{~Hz}$ repetition rate. The released electrons drift in an homogeneous electric field between two Rogowski profiled electrodes. Upon collision with sample gas molecules, ionization and attachment events lead to a growth or decrease of the electron swarm. The electrical displacement current across the gap is measured.

The electron swarm is modeled with a Gaussian spatial distribution of the electrons and the corresponding current can be expressed for $t \geq 0$ as [33]

$$
\begin{aligned}
& I_{\mathrm{e}}(t)=\frac{I_{0}}{2} \exp \left(\nu_{\mathrm{eff}} t\right)\left(1-\operatorname{erf}\left(\frac{t-T_{\mathrm{e}}}{\sqrt{2 \tau_{\mathrm{D}} t}}\right)\right), \\
& I_{0}=\frac{n_{0} q_{0}}{T_{\mathrm{e}}}
\end{aligned}
$$


where $q_{0}$ is the electron charge, $I_{0}$ is the electron current at time $t=0, T_{\mathrm{e}}$ is the drift time and $\nu_{\text {eff }}$ is the effective ionization rate. The canonical error function "erf" accounts for the absorption of the electrons at the anode. The characteristic time for longitudinal diffusion $\tau_{\mathrm{D}}$ is related to the longitudinal diffusion coefficient $D_{\mathrm{L}}$ via $2 D_{\mathrm{L}}=w^{2} \tau_{\mathrm{D}}$, where $w$ is the electron drift velocity. The initial distribution of the electrons released by the laser is assumed to be a Dirac delta. The analytical model (6) is fitted to the measured current as described in detail in [34] to obtain the electron swarm parameters $k_{\text {eff }}=\nu_{\text {eff }} / N, w$ and $N D_{\mathrm{L}}$.

The measurements were performed in pure $\mathrm{N}_{2}, \mathrm{CO}_{2}$ and $\mathrm{Ar}$, and in the mixtures of $0.6 \% \mathrm{c}-\mathrm{C}_{4} \mathrm{~F}_{8} \mathrm{O}$ in $\mathrm{N}_{2}, 0.5 \% \mathrm{c}-\mathrm{C}_{4} \mathrm{~F}_{8} \mathrm{O}$ in $\mathrm{CO}_{2}$ and $0.1 \% \mathrm{c}-\mathrm{C}_{4} \mathrm{~F}_{8} \mathrm{O}$ in Ar. The $\mathrm{c}-\mathrm{C}_{4} \mathrm{~F}_{8} \mathrm{O}$ has a purity of $99.5 \%$ (Linde), the $\mathrm{Ar}$ and $\mathrm{N}_{2}$ have a purity of 6.0 and the $\mathrm{CO}_{2}$ a purity of 5.0. The gases are filled into a vessel previously evacuated to a pressure of $\sim 1 \mathrm{~Pa}$. The total gas pressure was varied from 2 to $10.5 \mathrm{kPa}$, the electrode gap distance from 11 to $17 \mathrm{~mm}$, and the density reduced electric field $E / N$ from 5 to $135 \mathrm{Td}\left(1 \mathrm{Td}=10^{-21} \mathrm{~V} . \mathrm{m}^{2}\right)$.

\subsection{Results}

Sample current measurements in the mixtures of $0.6 \% \mathrm{c}_{-} \mathrm{C}_{4} \mathrm{~F}_{8} \mathrm{O}$ in $\mathrm{N}_{2}, 0.5 \% \mathrm{c}_{-} \mathrm{C}_{4} \mathrm{~F}_{8} \mathrm{O}$ in $\mathrm{CO}_{2}$ and $0.1 \% \mathrm{c}_{-} \mathrm{C}_{4} \mathrm{~F}_{8} \mathrm{O}$ in $\mathrm{Ar}$ are shown in figures 4,5 and 6 respectively. The
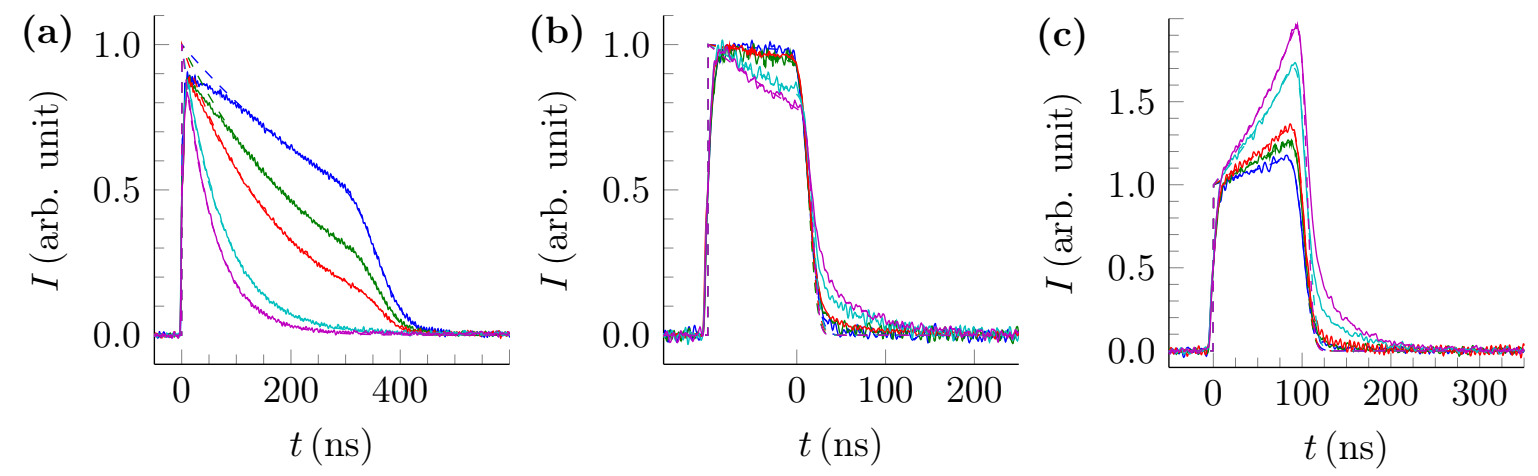

Figure 4: Current versus time in the mixture of $0.6 \% \mathrm{c}_{-} \mathrm{C}_{4} \mathrm{~F}_{8} \mathrm{O}$ in $\mathrm{N}_{2}$ (a) for $E / N \simeq$ $26 \mathrm{Td}$, (b) for $E / N \simeq 123 \mathrm{Td}$ and (c) for $E / N \simeq 137 \mathrm{Td}$, at different gas pressures and for an electrode gap distance of $15 \mathrm{~mm}$. In figure (a), the curves correspond from top to bottom to the pressures $2,3,4,8$ and $10 \mathrm{kPa}$, and the same color code is used in figures (b) and (c). The measured currents are in the range of 10 to $45 \mu \mathrm{A}$, they are here normalized so that the different curves have the same initial amplitude. The full lines are the measured currents, whereas the dashed lines correspond to fits of the analytical model (6).

analytical model (6) fits well all the measured currents, except the falling edge of the measured current at 8 and $10 \mathrm{kPa}$ in figure 4 (b) and (c), which is discussed later.

The effective ionization rate coefficient $k_{\text {eff }}$, electron drift velocity $w$ and longitudinal electron diffusion coefficient $N D_{\mathrm{L}}$ obtained experimentally in $\mathrm{N}_{2}, \mathrm{CO}_{2}$ and $\mathrm{Ar}$, and in 

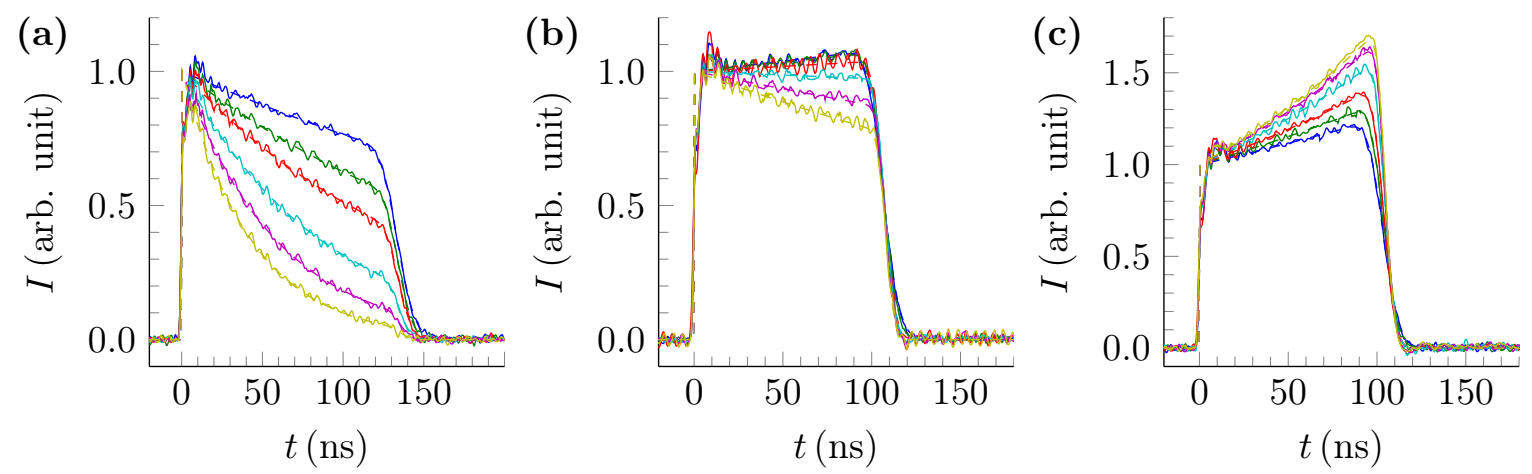

Figure 5: Current versus time in the mixture of $0.5 \% \quad \mathrm{c}_{-} \mathrm{C}_{4} \mathrm{~F}_{8} \mathrm{O}$ in $\mathrm{CO}_{2}$ (a) for $E / N \simeq 55 \mathrm{Td}$, (b) for $E / N \simeq 99 \mathrm{Td}$ and (c) for $E / N \simeq 105 \mathrm{Td}$, at different gas pressures and for an electrode gap distance of $15 \mathrm{~mm}$. In figure (a), the curves correspond from top to bottom to the pressures $2,3,4,6,8$ and $10 \mathrm{kPa}$, and the same color code is used in figures (b) and (c). The measured currents are in the range of 15 to $40 \mu \mathrm{A}$, they are here normalized so that the different curves have the same initial amplitude. The full lines are the measured currents, whereas the dashed lines correspond to fits of the analytical model (6).
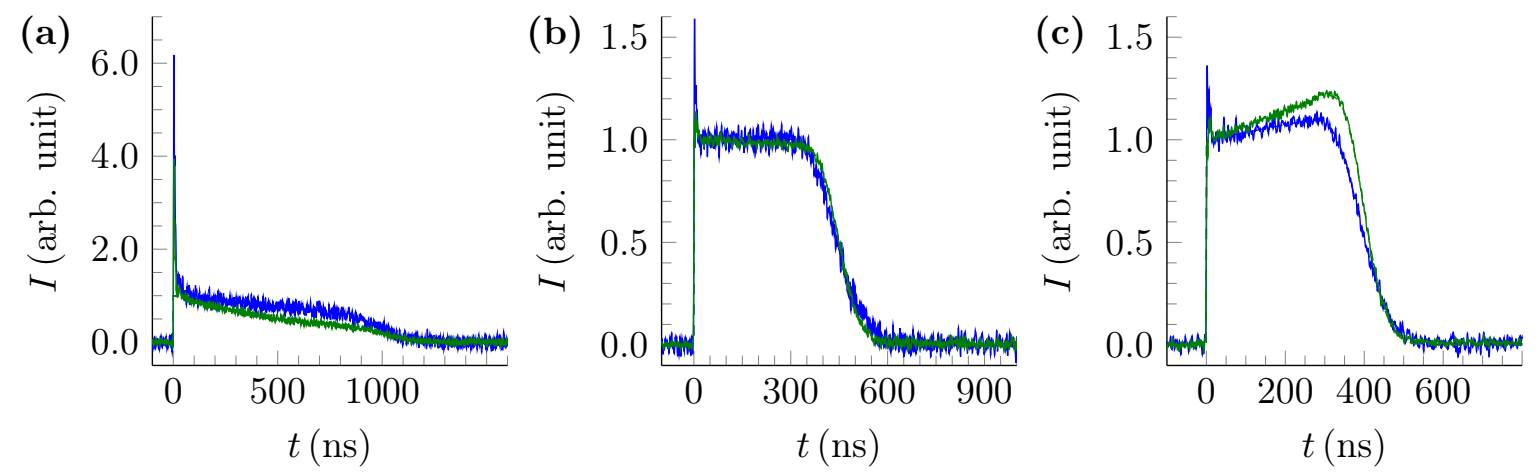

Figure 6: Current versus time in the mixture of $0.1 \% \quad \mathrm{c}_{-} \mathrm{C}_{4} \mathrm{~F}_{8} \mathrm{O}$ in $\mathrm{Ar}$ (a) for $E / N \simeq 6 \mathrm{Td}$, (b) for $E / N \simeq 26 \mathrm{Td}$ and (c) for $E / N \simeq 30 \mathrm{Td}$, at different gas pressures and for an electrode gap distance of $11 \mathrm{~mm}$. In figure (a), the curves correspond from top to bottom to the pressures 5 and $10 \mathrm{kPa}$, and the same color code is used in figures (b) and (c). The measured currents are in the range of 5 to $20 \mu \mathrm{A}$, they are here normalized so that the different curves have the same initial amplitude. The full lines are the measured currents, whereas the dashed lines correspond to fits of the analytical model (6).

the corresponding mixtures are shown in figures 7,8 and 9. This data is also available on the LXcat website, ETHZ database [35]. 
(a)

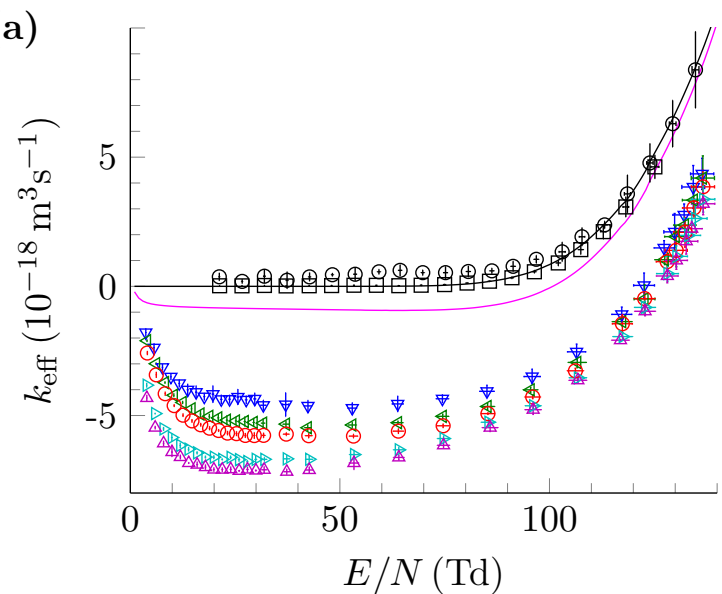

(c)

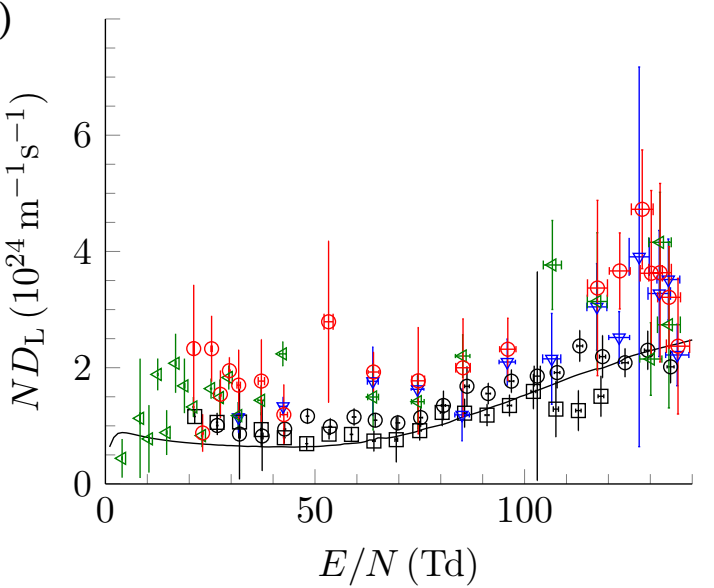

(b)

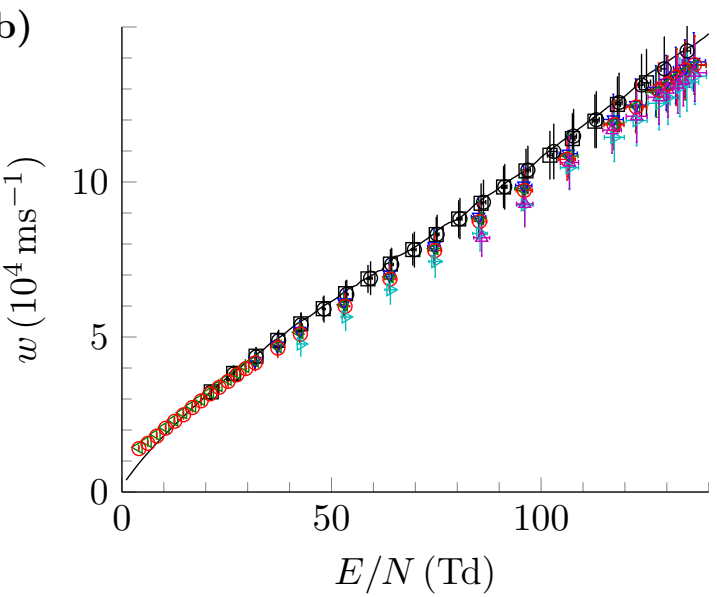

$\mathrm{N}_{2}$

$\begin{array}{ll}\text { Measurements } & \circ 2 \mathrm{kPa}, 10.5 \mathrm{kPa} \\ \text { Calculations } & -k_{\mathrm{eff}}^{\mathrm{b}}, w^{\mathrm{b}}, N D_{\mathrm{L}}^{\mathrm{b}}\end{array}$

$0.6 \% \mathrm{c}-\mathrm{C}_{4} \mathrm{~F}_{8} \mathrm{O}$ in $\mathrm{N}_{2}$

Measurements $\nabla 2 \mathrm{kPa} \triangleright 8 \mathrm{kPa}$

$\triangleleft 3 \mathrm{kPa} \quad \triangle 10 \mathrm{kPa}$

- $4 \mathrm{kPa}$

Calculation

Figure 7: (a) Effective ionization rate coefficient, (b) electron drift velocity and (c) density normalized longitudinal electron diffusion coefficient versus $E / N$ in $\mathrm{N}_{2}$ and in the mixture of $0.6 \% \quad \mathrm{c}_{4} \mathrm{C}_{4} \mathrm{~F}_{8} \mathrm{O}$ in $\mathrm{N}_{2}$. Markers are measured values at different gas pressures, lines are calculated as indicated in section 2 . 

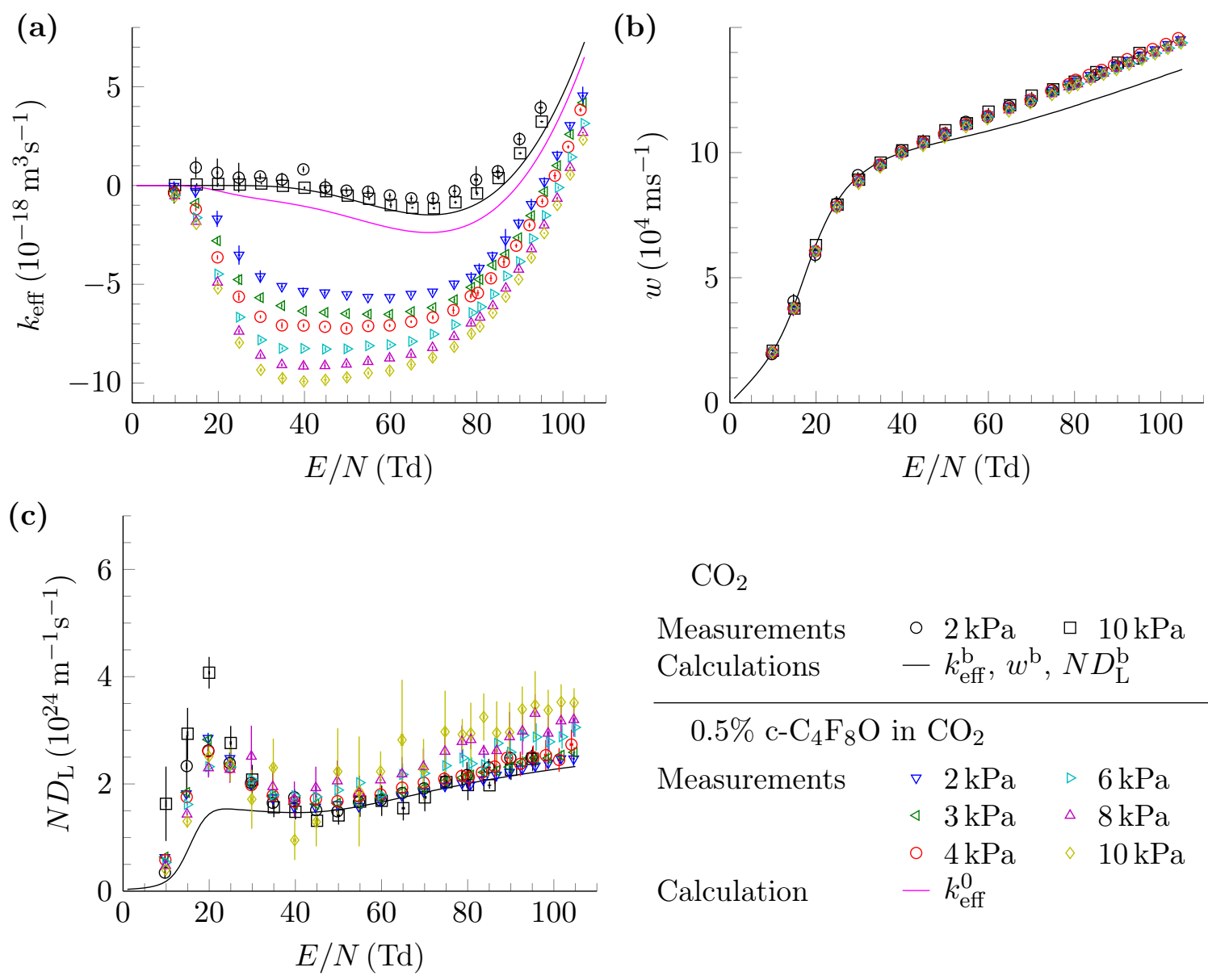

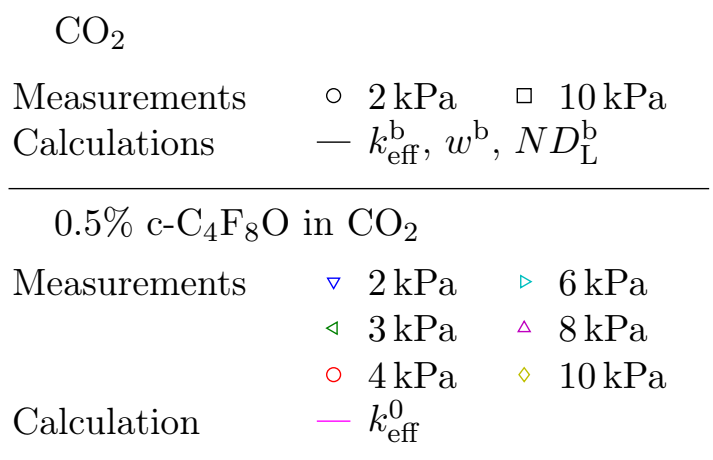

Figure 8: (a) Effective ionization rate coefficient, (b) electron drift velocity and (c) density normalized longitudinal electron diffusion coefficient versus $E / N$ in $\mathrm{CO}_{2}$ and in the mixture of $0.5 \% \quad \mathrm{c}_{4} \mathrm{C}_{4} \mathrm{~F}_{8} \mathrm{O}$ in $\mathrm{CO}_{2}$. Markers are measured values at different gas pressures, lines are calculated as indicated in section 2 . 

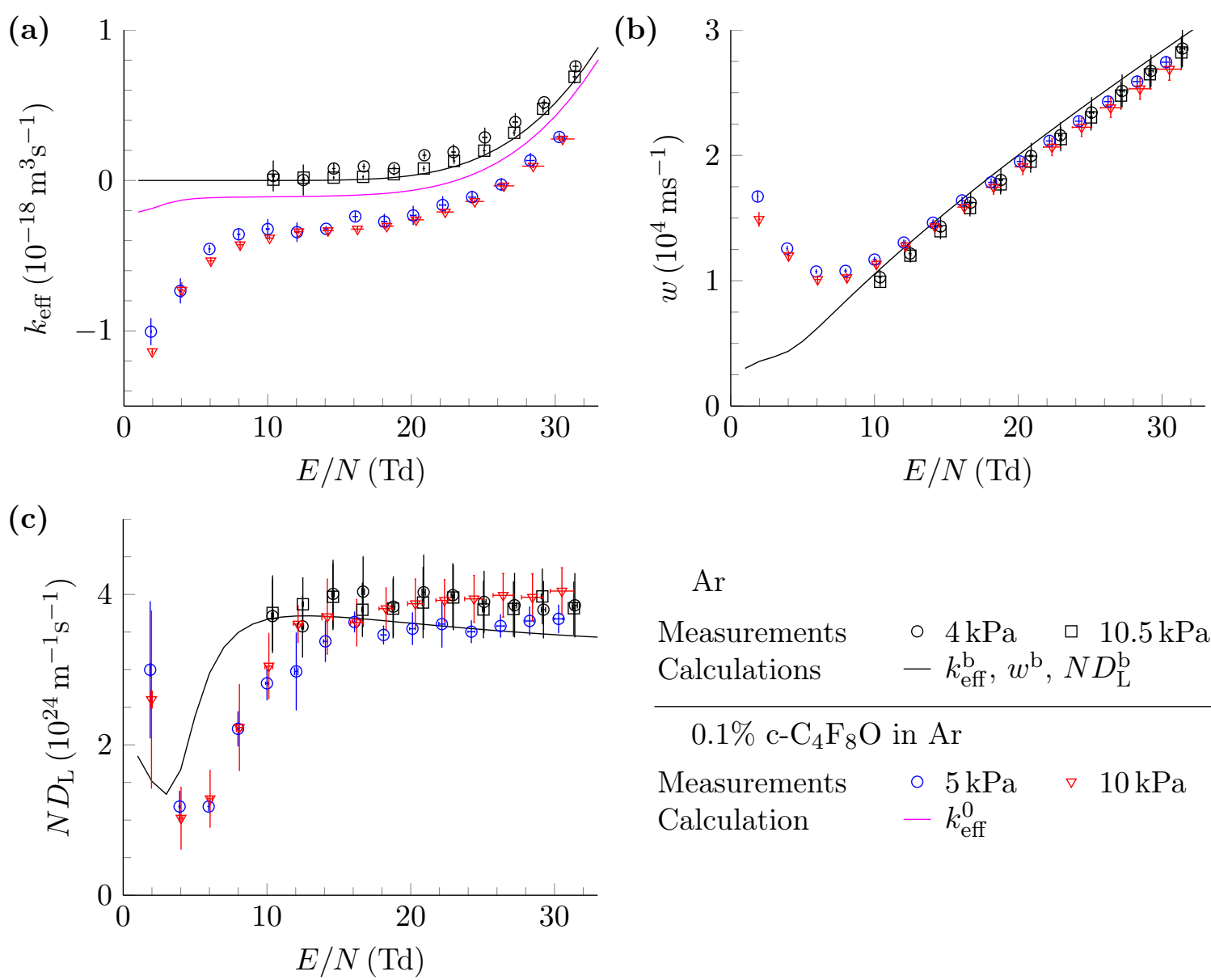

$$
\begin{aligned}
& \mathrm{Ar} \\
& \begin{array}{lll}
\text { Measurements } & \circ 4 \mathrm{kPa}, \quad \square 10.5 \mathrm{kPa} \\
\text { Calculations } & -k_{\mathrm{eff}}^{\mathrm{b}}, w^{\mathrm{b}}, N D_{\mathrm{L}}^{\mathrm{b}}
\end{array} \\
& 0.1 \% \mathrm{c}^{-} \mathrm{C}_{4} \mathrm{~F}_{8} \mathrm{O} \text { in } \mathrm{Ar} \\
& \text { Measurements } \circ 5 \mathrm{kPa} \quad \nabla 10 \mathrm{kPa} \\
& \text { Calculation } \quad-k_{\text {eff }}^{0}
\end{aligned}
$$

Figure 9: (a) Effective ionization rate coefficient, (b) electron drift velocity and (c) density normalized longitudinal electron diffusion coefficient versus $E / N$ in $\mathrm{Ar}$ and in the mixture of $0.1 \% \quad c-\mathrm{C}_{4} \mathrm{~F}_{8} \mathrm{O}$ in Ar. Markers are measured values at different gas pressures, lines are calculated as indicated in section 2 . 


\subsection{Discussion}

Measurements and calculations in the buffer gases. There is relatively good agreement between the measured effective ionization rate coefficient, electron drift velocity and density normalized longitudinal electron diffusion coefficient in pure $\mathrm{N}_{2}, \mathrm{CO}_{2}$ and $\mathrm{Ar}$, and the same quantities calculated with Bolsig + from the cross section sets [26, 27, 28]. The agreement is not perfect, but different cross section sets are available for these gases (see for instance the LXcat project [5]), and each set yields slightly different results. For instance the measured values in $\mathrm{CO}_{2}$ are in between the calculated values using the cross sections sets [27] and [28] for $\mathrm{CO}_{2}$ (the latter is not shown here). For the purpose of this work, the calculations from the sets $[26,27,28]$ are in sufficiently good agreement with the measurements.

Measurements of $w$ and $N D_{\mathrm{L}}$ in the $c-C_{4} F_{8} O$ mixtures. In the mixture of $0.6 \%$ c- $\mathrm{C}_{4} \mathrm{~F}_{8} \mathrm{O}$ in $\mathrm{N}_{2}$, at the pressures of 8 and $10 \mathrm{kPa}$, a residual current is measured after the electron transit, as shown in figure 4 (b) and (c) for times $t \geq 110 \mathrm{~ns}$. The falling edge of the waveform is asymmetrical, which indicates that the spatial distribution of electrons is not Gaussian. This asymmetrical broadening of the electron swarm could be due to delayed electrons, produced for instance via electron detachment from negative ions. Since the broadening of the swarm is different in the forward and backward directions, and is affected by another process than diffusion, the electron diffusion coefficient cannot be derived for these waveforms. Approximate values for the drift velocity at 8 and $10 \mathrm{kPa}$ are shown in figure 7 (c). The electron drift velocity $w$ measured in the mixture of $0.6 \%$ c- $\mathrm{C}_{4} \mathrm{~F}_{8} \mathrm{O}$ in $\mathrm{N}_{2}$ seems slightly lower than the measured and calculated velocities in pure $\mathrm{N}_{2}$, although it is still within the measurement error. The diffusion coefficient $N D_{\mathrm{L}}$ measured in the mixture of $0.6 \% \mathrm{c}_{-} \mathrm{C}_{4} \mathrm{~F}_{8} \mathrm{O}$ in $\mathrm{N}_{2}$ is slightly larger than the measured and calculated $N D_{\mathrm{L}}$ in pure $\mathrm{N}_{2}$.

The measured $w$ and $N D_{\mathrm{L}}$ in the mixture of $0.5 \% \mathrm{c}_{-} \mathrm{C}_{4} \mathrm{~F}_{8} \mathrm{O}$ in $\mathrm{CO}_{2}$ agree very well with the measured $w$ and $N D_{\mathrm{L}}$ in pure $\mathrm{CO}_{2}$ as shown in figure 8 (b) and (c).

In the mixture of $0.1 \% \mathrm{c}_{-} \mathrm{C}_{4} \mathrm{~F}_{8} \mathrm{O}$ in $\mathrm{Ar}$, in the range $E / N<10 \mathrm{Td}$, w strongly deviates from the measured and calculated values of $w$ in pure Ar shown in figure 9 (b). Such a change in $w$ indicates a change of EEDF in the mixture. This makes the calculation of $k_{\text {eff }}^{0}$ in the $\mathrm{c}_{-} \mathrm{C}_{4} \mathrm{~F}_{8} \mathrm{O} / \mathrm{Ar}$ mixture in section 2 less reliable. The same effect was observed in [36] for small admixtures about $0.5 \%$ of octafluorocyclobutane $c-\mathrm{C}_{4} \mathrm{~F}_{8}$ in Ar. This decrease of the drift velocity, often referred to as negative differential mobility or negative differential conductivity, has been studied extensively [37, 38, 39] and is considered common for diluted mixtures of molecular gases in Ar.

Measurements and calculations of $k_{\mathrm{eff}}$ in the $c-C_{4} F_{8} O$ mixtures. The measurements of $k_{\text {eff }}$ show that the addition of small amounts of $\mathrm{c}_{-} \mathrm{C}_{4} \mathrm{~F}_{8} \mathrm{O}$ in $\mathrm{N}_{2}, \mathrm{CO}_{2}$ and Ar strongly decreases $k_{\text {eff }}$, and thus increases the density reduced critical electrical field $(E / N)_{\text {crit }}$ for which $k_{\text {eff }}=0$. This increase of $(E / N)_{\text {crit }}$ is advantageous for electrical insulation 
applications. In all three mixtures the calculated values of $k_{\text {eff }}^{0}$ from section 2 clearly do not agree with the measured values of $k_{\text {eff }}$. They differ by approximately a factor of 5. Moreover, a strong pressure dependency of $k_{\text {eff }}$ is observed in the $c_{-} \mathrm{C}_{4} \mathrm{~F}_{8} \mathrm{O} / \mathrm{N}_{2}$ and $c-\mathrm{C}_{4} \mathrm{~F}_{8} \mathrm{O} / \mathrm{CO}_{2}$ mixtures. Since the electron kinetics scheme (1-3) obtained with the beam experiment fails to explain the swarm results, a model including three-body electron attachment is introduced in section 4.

\section{Three-body attachment model}

The importance of the density of the gaseous media on electron attachment is well known [13]. Complex molecules such as $\mathrm{c}_{-} \mathrm{C}_{4} \mathrm{~F}_{8} \mathrm{O}$, when capturing a free electron, can form a large number of unstable negative-ion states, also called parent anions. Parent ions have typically short autodetachment times due to their excess energy, but they can be stabilized upon collision with another molecule. In the beam experiment, due to the low pressure of the gas target, the ion-neutral collision timescale is about $10^{-4} \mathrm{~s}$, and the anion extraction time is about $10^{-6} \mathrm{~s}$. The collisional stabilization of parent ions is therefore negligible, and only stable anions and long-lived (mean autodetachment time $>10^{-6} \mathrm{~s}$ ) parent anions are detected. In swarm experiments however, the collisions occur on the sub-nanosecond timescale, so that short-lived parent anions can significantly contribute to electron attachment via a three-body attachment mechanism. Furthermore, as the stabilization time depends on the gas pressure, threebody attachment results in a pressure dependence of $k_{\text {eff }}$.

\subsection{Three-body attachment mechanism}

In this model, additionally to the electron kinetic processes discussed in section 2, it is assumed that one additional unstable negative-ion state is formed, with an autodetachment time too short to be detected in the beam experiment but sufficiently long to allow stabilization in the swarm experiment. This short-lived parent anion, will be noted in the following $\left(\mathrm{C}_{4} \mathrm{~F}_{8} \mathrm{O}^{-}\right)_{\mathrm{S}}^{*}$. Three-body attachment can be described by the processes

$$
\begin{aligned}
& \mathrm{C}_{4} \mathrm{~F}_{8} \mathrm{O}+e \underset{\tau^{-1}}{\stackrel{k_{\text {at }}}{\rightleftarrows}}\left(\mathrm{C}_{4} \mathrm{~F}_{8} \mathrm{O}^{-}\right)_{\mathrm{S}}^{*} \text { (parent ion attachment, short-lived), } \\
& \left(\mathrm{C}_{4} \mathrm{~F}_{8} \mathrm{O}^{-}\right)_{\mathrm{S}}^{*}+\mathrm{M} \stackrel{k_{\text {stab }}}{\longrightarrow} \mathrm{C}_{4} \mathrm{~F}_{8} \mathrm{O}^{-}+\mathrm{M} \text { (collisional stabilization), } \\
& \left(\mathrm{C}_{4} \mathrm{~F}_{8} \mathrm{O}^{-}\right)_{\mathrm{S}}^{*}+\mathrm{M} \stackrel{k_{\text {det }}}{\longrightarrow} e+\mathrm{C}_{4} \mathrm{~F}_{8} \mathrm{O}+\mathrm{M} \text { (collisional detachment). }
\end{aligned}
$$

In the above mechanism, $k_{\text {at }}$ is the rate coefficient of $\left(\mathrm{C}_{4} \mathrm{~F}_{8} \mathrm{O}^{-}\right)_{\mathrm{S}}^{*}$ formation, $\tau$ is the lifetime of $\left(\mathrm{C}_{4} \mathrm{~F}_{8} \mathrm{O}^{-}\right)_{\mathrm{S}}^{*}$ towards autodetachment, $k_{\text {stab }}$ is the rate coefficient for collisional stabilization of $\left(\mathrm{C}_{4} \mathrm{~F}_{8} \mathrm{O}^{-}\right)_{\mathrm{S}}^{*}$ by a buffer gas molecule $\mathrm{M}$, and $k_{\text {det }}$ is the rate coefficient of electron detachment from $\left(\mathrm{C}_{4} \mathrm{~F}_{8} \mathrm{O}^{-}\right)_{\mathrm{S}}^{*}$ upon collision with buffer gas molecule M. Since it is not a priori known at which electron energy this short-lived parent ion is formed, the channel (8) is considered distinct from the dissociative attachment channels. 
The mechanism (1-3) and (8-10) corresponds to a system of differential equations for the densities of electrons and ions. Through the processes (8-10), the density of electrons is coupled with that of $\left(\mathrm{C}_{4} \mathrm{~F}_{8} \mathrm{O}^{-}\right)_{\mathrm{S}}^{*}$. After a few $\tau$, the growth of the electron number is exponential, with the rate $[34,40]$

$$
\nu_{\text {eff }}(N)=k_{\text {eff }}^{\mathrm{b}}[\mathrm{M}]+\left(k_{\mathrm{i}}-k_{\mathrm{da}}-k_{\mathrm{pa}}\right)\left[\mathrm{C}_{4} \mathrm{~F}_{8} \mathrm{O}\right]-\frac{k_{\mathrm{at}} k_{\mathrm{stab}} \tau\left[\mathrm{C}_{4} \mathrm{~F}_{8} \mathrm{O}\right][\mathrm{M}]}{1+\tau\left(k_{\mathrm{det}}+k_{\mathrm{stab}}\right)[\mathrm{M}]}
$$

The number concentrations $[\mathrm{M}]$ and $\left[\mathrm{C}_{4} \mathrm{~F}_{8} \mathrm{O}\right]$ can be expressed as a function of the total gas number density $N$ and the ratio $r$ of $\mathrm{c}_{-} \mathrm{C}_{4} \mathrm{~F}_{8} \mathrm{O}$

$$
\begin{aligned}
& {[\mathrm{M}]=(1-r) N,} \\
& {\left[\mathrm{C}_{4} \mathrm{~F}_{8} \mathrm{O}\right]=r N .}
\end{aligned}
$$

We recognize the term $k_{\text {eff }}^{\mathrm{b}}[\mathrm{M}]+\left(k_{\mathrm{i}}-k_{\mathrm{da}}-k_{\mathrm{pa}}\right)\left[\mathrm{C}_{4} \mathrm{~F}_{8} \mathrm{O}\right]=k_{\text {eff }}^{0}(r) N$ calculated in section 2 . Since we consider small ratios $(r \ll 1)$ of $\mathrm{c}_{-} \mathrm{C}_{4} \mathrm{~F}_{8} \mathrm{O}$, we make the simplification

$$
[\mathrm{M}] \approx N .
$$

Furthermore, in the following we use the notations

$$
\begin{aligned}
& k_{\text {quad }}=k_{\text {at }} k_{\text {stab }} \tau, \\
& N_{\text {sat }}=\left(\left(k_{\text {stab }}+k_{\text {det }}\right) \tau\right)^{-1}, \\
& k_{\text {sat }}=k_{\text {quad }} N_{\text {sat }} .
\end{aligned}
$$

Adopting the above notations, equation (11) becomes

$$
\nu_{\text {eff }}(N)=k_{\text {eff }}^{0}(r) N-\frac{k_{\text {quad }} r N^{2}}{1+N / N_{\text {sat }}} .
$$

The effective ionization rate $\nu_{\text {eff }}$ is a strong function of the gas density $N$ in the experiment. By comparing $N$ to $N_{\text {sat }}$, two limiting cases can be identified [40]

(i) When $N \ll N_{\text {sat }}$, equation (18) simplifies as

$$
\nu_{\text {eff }}(N)=k_{\text {eff }}^{0}(r) N-k_{\text {quad }} r N^{2},
$$

and the three-body attachment rate increases quadratically with the gas density.

(ii) When $N \gg N_{\text {sat }}$, equation (18) simplifies as

$$
\nu_{\text {eff }}(N)=k_{\text {eff }}^{0}(r) N-k_{\text {sat }} r N,
$$

and the three-body attachment rate increases linearly with the gas density.

Thus, the quantity $N_{\text {sat }}$ can be seen as a "saturation" density for three-body attachment.

\subsection{Rate coefficients and saturation density for three-body attachment to c- $C_{4} F_{8} O$}

The simple model for the three-body electron attachment to $\mathrm{c}_{-} \mathrm{C}_{4} \mathrm{~F}_{8} \mathrm{O}$ described in section 4.1 enables us to quantitatively characterize the kinetic processes (8-10) by determining $N_{\text {sat }}, k_{\text {sat }}$ and $k_{\text {quad }}$.

For measurements in the $\mathrm{c}_{-} \mathrm{C}_{4} \mathrm{~F}_{8} \mathrm{O} / \mathrm{N}_{2}$ and $\mathrm{c}-\mathrm{C}_{4} \mathrm{~F}_{8} \mathrm{O} / \mathrm{CO}_{2}$ mixtures, the observed dependency of $\nu_{\text {eff }}(N)$ corresponds not to either limiting cases (i) and (ii) but to the 
general case (18), where $N_{\text {sat }}$ may be of the same order of magnitude as $N\left(N_{\text {sat }} \sim N\right)$. Therefore $k_{\text {quad }}$ and $N_{\text {sat }}$ are directly obtained from the fit of equation (18) to the measured $\nu_{\text {eff }}(N)$. The rate coefficient $k_{\text {sat }}$ is obtained simultaneously as the product $k_{\text {quad }} N_{\text {sat }}$ from equation (17). Examples of the fit of equation (18) on the measured $\nu_{\text {eff }}(N)$ are shown in figure $10\left(\right.$ a) for the $\mathrm{N}_{2}$ mixture and in figure $10(\mathrm{~b})$ for the $\mathrm{CO}_{2}$ mixture.
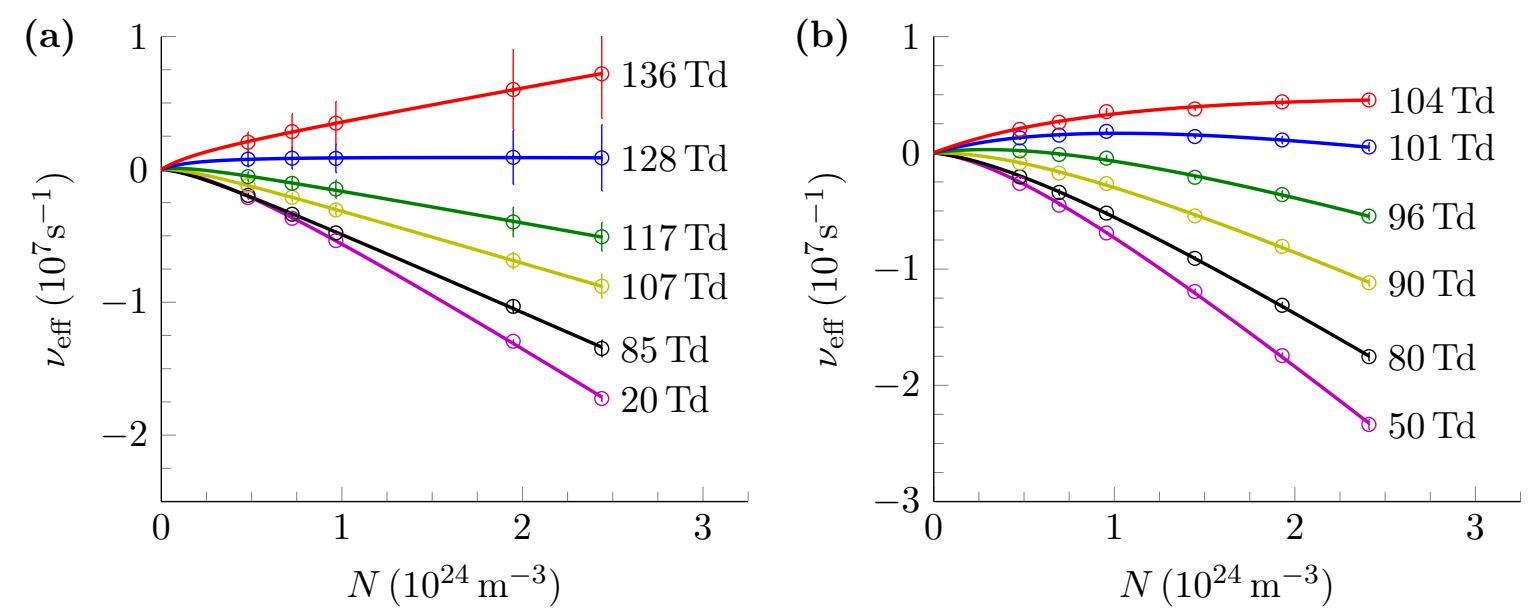

Figure 10: $\nu_{\text {eff }}$ as a function of $N$ (a) in the $\mathrm{c}_{-} \mathrm{C}_{4} \mathrm{~F}_{8} \mathrm{O} / \mathrm{N}_{2}$ mixture for sample $E / N$ values between 20 and $135 \mathrm{Td}$ and (b) in the $\mathrm{c}_{-} \mathrm{C}_{4} \mathrm{~F}_{8} \mathrm{O} / \mathrm{CO}_{2}$ mixture for sample $E / N$ values between 50 and $104 \mathrm{Td}$. Markers are measured values of $\nu_{\text {eff }}$, and lines are fits with equation (18).

In the $\mathrm{c}-\mathrm{C}_{4} \mathrm{~F}_{8} \mathrm{O} / \mathrm{Ar}$ mixture, the measured $k_{\text {eff }}$ is independent from the gas density. Normally, this could be interpreted as the absence of three-body attachment, but $k_{\text {eff }}$ is much lower than $k_{\text {eff }}^{0}$ calculated with the electron kinetics scheme from section 2 . Thus, the measurements in the $\mathrm{c}_{-} \mathrm{C}_{4} \mathrm{~F}_{8} \mathrm{O} / \mathrm{Ar}$ mixture correspond rather to the regime of saturated three-body attachment (ii). In this case, the saturated three-body attachment rate coefficient $k_{\text {sat }}$ can be obtained as $\left(k_{\text {eff }}^{0}-k_{\text {eff }}\right) / r$ from equation (20). However, the calculation of $k_{\text {eff }}^{0}$ in the $c-\mathrm{C}_{4} \mathrm{~F}_{8} \mathrm{O} / \mathrm{Ar}$ mixture is probably imprecise, because the drift velocity measured in the $\mathrm{c}_{-} \mathrm{C}_{4} \mathrm{~F}_{8} \mathrm{O} / \mathrm{Ar}$ mixture indicates that the EEDF deviates from the EEDF of pure Argon, as mentioned in section 3.3.

The quadratic three-body attachment rate coefficient $k_{\text {quad }}$, the saturation density $N_{\text {sat }}$ and the saturated three-body attachment rate coefficient $k_{\text {sat }}$ in the $c_{-} \mathrm{C}_{4} \mathrm{~F}_{8} \mathrm{O} / \mathrm{N}_{2}$ and $\mathrm{c}_{-} \mathrm{C}_{4} \mathrm{~F}_{8} \mathrm{O} / \mathrm{CO}_{2}$ mixtures are shown in figure 11. The saturation density $N_{\text {sat }}$ is of the same order of magnitude as the gas density in the swarm experiment.

Interestingly, since the swarm measurements in the $\mathrm{c}-\mathrm{C}_{4} \mathrm{~F}_{8} \mathrm{O} / \mathrm{N}_{2}$ and $\mathrm{c}-\mathrm{C}_{4} \mathrm{~F}_{8} \mathrm{O} / \mathrm{CO}_{2}$ mixtures were performed in the pressure range where $N_{\text {sat }} \sim N$, it was possible to identify both $k_{\text {quad }}$ and $N_{\text {sat }}$. This makes it possible to calculate $k_{\text {eff }}$ at at arbitrary gas pressure (provided that the pressure of $\mathrm{c}_{-} \mathrm{C}_{4} \mathrm{~F}_{8} \mathrm{O}$ stays below its vapor pressure) and arbitrary low concentrations of $\mathrm{c}_{-} \mathrm{C}_{4} \mathrm{~F}_{8} \mathrm{O}(r \ll 1)$ in the buffer gases $\mathrm{N}_{2}$ and $\mathrm{CO}_{2}$ using equation (18). In particular the limit of $k_{\text {eff }}(N)$ at low gas pressure is given by $k_{\text {eff }}^{0}(r)$ 


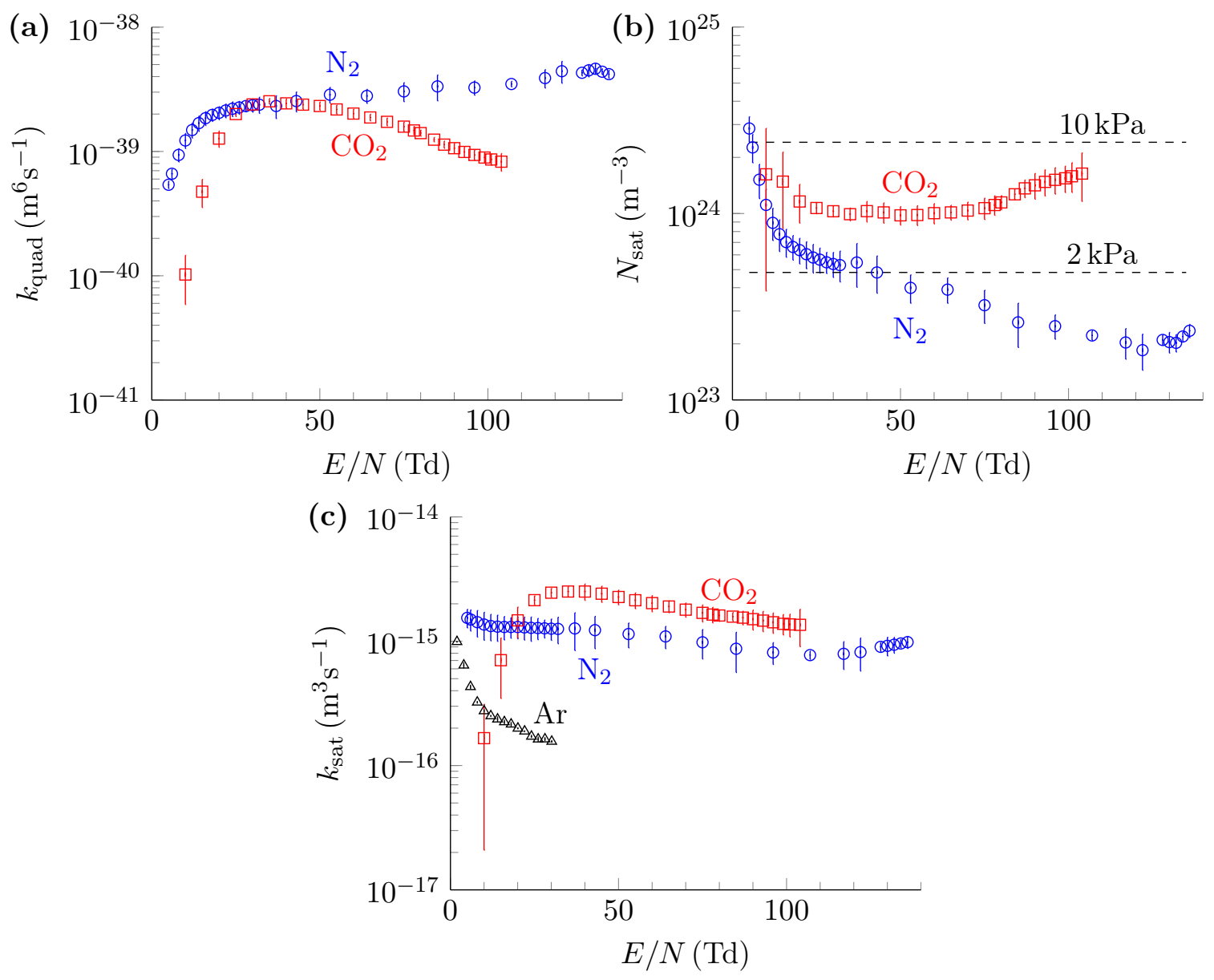

Figure 11: (a) Quadratic three-body attachment rate coefficient $k_{\text {quad }}$, (b) density of saturation $N_{\text {sat }}$ and (c) saturated three-body attachment rate coefficient $k_{\text {sat }}$ as a function of $\mathrm{E} / \mathrm{N}$ in $\mathrm{N}_{2}$ and $\mathrm{CO}_{2}$.

and the limit of $k_{\text {eff }}(N)$ at high pressure is given by $k_{\text {eff }}^{\infty}=k_{\text {eff }}^{0}(r)-r k_{\text {sat }}$. The possibility to calculate $k_{\text {eff }}$ for other low concentrations of $\mathrm{c}_{-} \mathrm{C}_{4} \mathrm{~F}_{8} \mathrm{O}$ is not explored in this work. However, $k_{\text {eff }}$ is calculated at different pressures, between $0.1 \mathrm{kPa}$ and $100 \mathrm{kPa}$ in the mixtures of $0.6 \% \mathrm{c}_{-} \mathrm{C}_{4} \mathrm{~F}_{8} \mathrm{O}$ in $\mathrm{N}_{2}$ and $0.5 \% \mathrm{c}-\mathrm{C}_{4} \mathrm{~F}_{8} \mathrm{O}$ in $\mathrm{CO}_{2}$. The calculated $k_{\text {eff }}$ are shown in figure $12(\mathrm{a})$ and (b). The limits of $k_{\text {eff }}$ at low and high pressures, $k_{\text {eff }}^{0}$ and $k_{\text {eff }}^{\infty}$, are shown as well. It is instructive to visualize the evolution of $k_{\text {eff }}(N)$ in figure 12 , because it makes the link between the (low pressure) beam and (high pressure) swarm results. Towards low gas pressures, the calculated effective ionization rate $k_{\text {eff }}(N)$ approaches $k_{\text {eff }}^{0}$ that was calculated from the beam cross sections with equation (5). This is expected, since the model was constructed based on the beam data. However, it can be seen that at pressures as low as a few millibar, three-body attachment is already significant. The calculations of $k_{\text {eff }}$ at high pressures, in particular the limit $k_{\text {eff }}^{\infty}$, can be of interest for instance for high voltage insulation applications, where pressures of a few bars are used. 

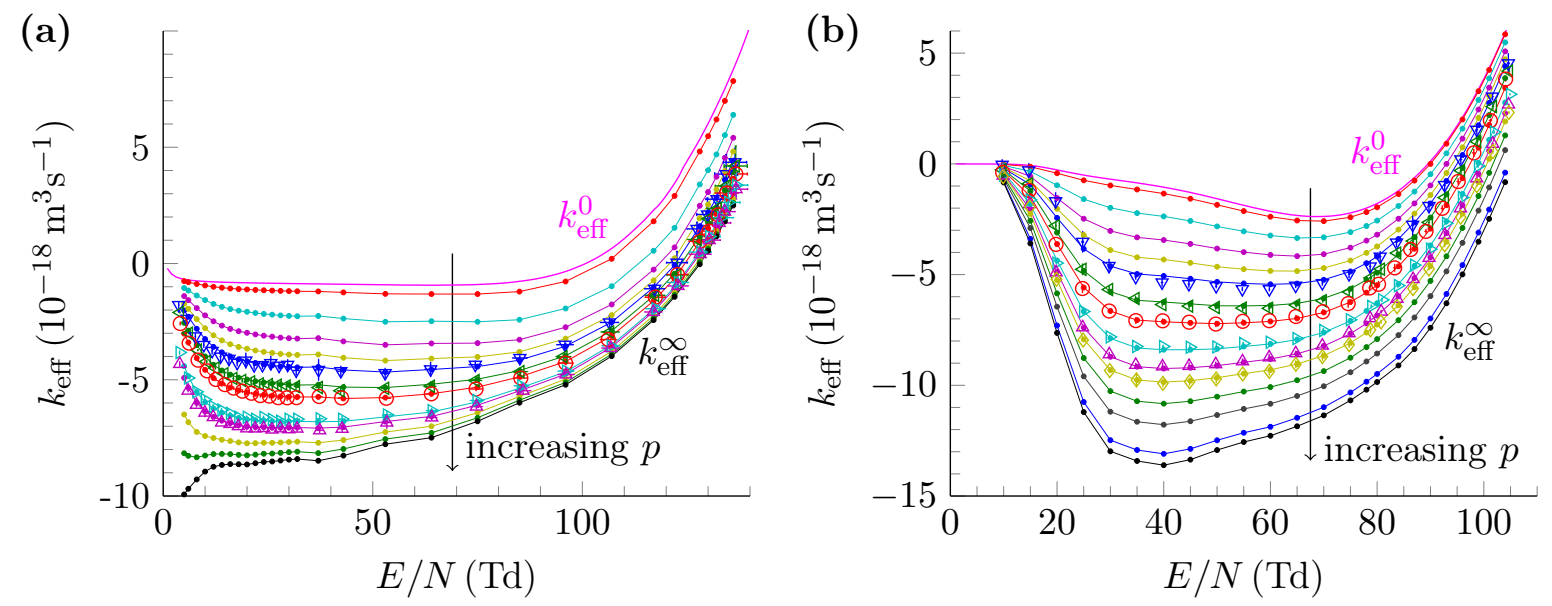

Figure 12: Measured and calculated effective ionization rate coefficient as a function of $E / N$. (a) In the mixture $0.6 \% \mathrm{c}_{-} \mathrm{C}_{4} \mathrm{~F}_{8} \mathrm{O}$ in $\mathrm{N}_{2}$ for the pressures $p \rightarrow 0\left(k_{\text {eff }}^{0}\right), p=0.1$, $0.5,1,1.5,2,3,4,8,10,20$ and $50 \mathrm{kPa}$, and $p \rightarrow \infty\left(k_{\text {eff }}^{\infty}\right)$. (b) In the mixture $0.5 \%$ c- $\mathrm{C}_{4} \mathrm{~F}_{8} \mathrm{O}$ in $\mathrm{CO}_{2}$ for the pressures $p \rightarrow 0$ ( $\left.k_{\text {eff }}^{0}\right), p=0.1,0.5,1,1.5,2,3,4,6,8,10,15$, 25 and $100 \mathrm{kPa}$, and $p \rightarrow \infty\left(k_{\text {eff }}^{\infty}\right)$.

\subsection{Discussion}

As the electron kinetics scheme identified with the beam study fails to explain attachment in $\mathrm{c}-\mathrm{C}_{4} \mathrm{~F}_{8} \mathrm{O}$ at superior gas pressure in the swarm experiment, a three-body attachment scheme was introduced. This model explains the strong pressure dependence of the effective ionization rate observed in the swarm study. Similar dependencies of the effective ionization rate on the gas pressure or temperature were observed in numerous other gases [34, 40,41] and were attributed to the occurrence of three-body electron attachment. Thus the occurrence of three-body attachment to $c-\mathrm{C}_{4} \mathrm{~F}_{8} \mathrm{O}$ is quite plausible. However, three-body attachment could occur with a more complex scheme than the one presently used. Some models were proposed for instance involving ion clusters [42]. In the present work, the kinetics scheme was chosen to be as simple as possible but consistent with the measured data. Thus, it should be seen only as a first attempt to explain the complex electron attachment mechanism to $c-\mathrm{C}_{4} \mathrm{~F}_{8} \mathrm{O}$, and a useful guess tool for extending the present data to higher pressures. An analysis of the ion composition produced in the swarm experiment would be a possible approach to gain more information on the attachment mechanism to $\mathrm{c}-\mathrm{C}_{4} \mathrm{~F}_{8} \mathrm{O}$.

\section{Conclusion}

In conclusion, we have measured electron attachment properties of $c-\mathrm{C}_{4} \mathrm{~F}_{8} \mathrm{O}$ in two different environments. The electron attachment and ionization cross sections of $\mathrm{c}-\mathrm{C}_{4} \mathrm{~F}_{8} \mathrm{O}$ were obtained using a beam experiment. The effective ionization rates in the diluted mixtures of $\mathrm{c}_{-} \mathrm{C}_{4} \mathrm{~F}_{8} \mathrm{O}$ in buffer gases in the pressure range $2-10 \mathrm{kPa}$ 
were obtained using a swarm experiment. The pressure difference between the two experiments - approximately five orders of magnitude - leads to dramatic changes in attachment properties of $\mathrm{c}_{-} \mathrm{C}_{4} \mathrm{~F}_{8} \mathrm{O}$. Therefore, a three-body attachment model was proposed. This model explains the increased electron attachment observed in the swarm experiment, provides a direct link between low-pressure and high-pressure data, and predicts the effective ionization rate of $c-\mathrm{C}_{4} \mathrm{~F}_{8} \mathrm{O}$ mixtures with $\mathrm{N}_{2}$ and $\mathrm{CO}_{2}$ at conditions beyond the range of the present experiments.

\section{Acknowledgments}

Thanks to N. Aleksandrov for kind explanations. This work is financially supported by GE Grid (Switzerland) GmbH, Pfiffner AG and ABB Switzerland. We also gratefully acknowledge the Swiss National Science Foundation (SNSF Project No. PZ00P2_132357) and the Scientific Exchange Programme (SCIEX Project 12.224).

\section{References}

[1] Artuso $\mathrm{M}$ et al. 2006 Performance of a $\mathrm{C}_{4} \mathrm{~F}_{8} \mathrm{O}$ gas radiator ring imaging Cherenkov detector using multi-anode photomultiplier tubes, Nuclear Instr. and Meth. in Phys. Research A 558373

[2] Kim K J et al. 2004 Global warming gas emission during plasma cleaning process of silicon nitride using c- $\mathrm{C}_{4} \mathrm{~F}_{8} \mathrm{O} / \mathrm{O}_{2}$ chemistry with additive $\mathrm{Ar}$ and $\mathrm{N}_{2}$, J. Vac. Sci. Technol. B 22483

[3] Myhre G, Shindell D, Bron F-M, Collins W, Fuglestvedt J, Huang J, Koch D, Lamarque JF, Lee D, Mendoza B, Nakajima T, Robock A, Stephens G, Takemura T and Zhang H 2013 Anthropogenic and Natural Radiative Forcing. In: Climate Change 2013: The Physical Science Basis. Contribution of Working Group I to the Fifth Assessment Report of the Intergovernmental Panel on Climate Change [Stocker, T.F., D. Qin, G.-K. Plattner, M. Tignor, S.K. Allen, J. Boschung, A. Nauels, Y. Xia, V. Bex and P.M. Midgley (eds.)]. Cambridge University Press, Cambridge, United Kingdom and New York, NY, USA, $p 731$

[4] Robson R E, Nicoletopoulos P, Li B and White R D 2008 Kinetic theoretical and fluid modelling of plasmas and swarms: the big picture, Plasma Sources Sci. Technol. $\mathbf{1 7}$

[5] Pancheshnyi S et al. 2012 The LXCat project: Electron scattering cross sections and swarm parameters for low temperature plasma modeling, Chem. Phys. 398148153

[6] Christophorou L G 1988 Insulating gases Nucl. Instr. and Meth. A 268 424-433

[7] Franck C M, Dahl D A, Rabie M, Haefliger P, and Koch M 2013 An efficient procedure to identify and quantify new molecules for insulating gas mixtures, Contrib. Plasma Phys. 54 3-13

[8] Hagelaar G J M and Pitchford L C 2005 Solving the Boltzmann equation to obtain electron transport coefficients and rate coefficients for fluid models, Plasma Sources Sci. Technol. 14722

[9] Biagi S F 1999 Monte Carlo simulation of electron drift and diffusion in counting gases under the inluence of electric and magnetic fields Nucl. Instr. and Meth. A 421 234-240

[10] Rabie M and Franck C M 2016 METHES: A Monte Carlo collision code for the simulation of electron transport in low temperature plasmas Comput. Phys. Commun. 203 268-277

[11] Christophorou L G (Ed.) 1984 Electron-molecule interactions and their applications Vol. 1 Academic Press

[12] Compton R N, Christophorou L G, Hurst G S, and Reinhardt P W 1966 Nondissociative Electron Capture in Complex Molecules and Negative-Ion Lifetimes, J. Chem. Phys. 454634

[13] Christophorou L G and Hunter S R 1984 Electrons in dense gases. In: Swarms of Ions and Electrons in Gases, Lindinger W, Mark T D and Howorka F, Springer-Verlag 
[14] Gallagher J W, Beaty E C, Dutton J, and Pitchford L C 1983 An Annotated Compilation and Appraisal of Electron Swarm Data in Electronegative Gases, J. Phys. Chem. Ref. Data 12109

[15] Dahl D A, Rabie M, Haefliger P, Franck C M 2014 Electron attaching properties of c- $\mathrm{C}_{4} \mathrm{~F}_{8} \mathrm{O}$ derived from swarm parameter measurements in buffer gases, Conference Paper Gas Discharges Orleans

[16] Fedor J, May O, Allan M 2008 Absolute cross sections for dissociative electron attachment to $\mathrm{HCl}$, $\mathrm{HBr}$, and their deuterated analogs, Phys. Rev. A $\mathbf{7 8} 032701$

[17] May O, Fedor J, Allan M 2009 Isotope effect in dissociative electron attachment to acetylene, Physical Review A $\mathbf{7 8} 012706$

[18] Janečková R, May O, Milosavljević A, Fedor J 2014 Partial cross sections for dissociative electron attachment in tetrahydrofuran reveal a dynamics-driven rich fragmentation pattern, Int. J. Mass. Spetrom. 163 365-366

[19] May O, Fedor J, Ibnescu B C, Allan M 2008 Absolute cross sections for dissociative electron attachment to acetylene and diacetylene, Phys. Rev. A 77 040701(R)

[20] Janečková R, Kubala D, May O, Fedor J, Allan M 2013 Experimental evidence on the mechanism of dissociative electron attachment to formic acid, Phys. Rev. Lett. 111213201

[21] Straub H C, Renault P, Lindsay B G, Smith K A, Stebbings R F 1995 Absolute partial and total cross sections for electron-impact ionization of argon from threshold to $1000 \mathrm{eV}$, Phys. Rev. A $\mathbf{5 2} 1115$

[22] Janečková R, Kočišek $J$, Fedor $J$, Unusually long-lived transient negative ion of $c_{-} \mathrm{C}_{4} \mathrm{~F}_{8} \mathrm{O}$, in preparation

[23] Gstir B, Hanel G, Fedor J, Probst M, Scheier P, Mason N J, Märk T D 2002 Electron impact ionization studies for $\mathrm{SF}_{5} \mathrm{CF}_{3}$, J. Phys. B: At. Mol. Opt. Phys. 352567

[24] Hanel G, Fedor J, Gstir B, Probst M, Scheier P, Märk T D, Tegeder P, Mason N J 2002 Electron impact ionization studies for $\mathrm{Cl}_{2} \mathrm{O}$ monomers and dimers, J. Phys. B: At. Mol. Opt. Phys. 35 589

[25] LXCAT Plasma Data Exchange Project, http://www.lxcat.net

[26] Biagi-v8.9 database, www.lxcat.net, retrieved 18/03/2014.

[27] Phelps database, www.lxcat.net, retrieved 27/06/2014.

[28] SIGLO database, www.lxcat.net, retrieved 05/07/2014.

[29] Blevin H A, Fletcher J and Hunter S R 1985 Electron-velocity distribution functions in gases: The influence of anisotropic scattering and electron nonconservation by attachment and ionization, Phys. Rev. A 312215

[30] Bordage M C, Segur P and Chouki A 1996 Determination of a set of electron impact cross sections in tetrafluoromethane consistent with experimental determination of swarm parameters, J. Appl. Phys $\mathbf{8 0} 1325$

[31] Phelps A V, Pitchford L C 1985 Anisotropic scattering of electrons by $\mathrm{N}_{2}$ and its effect on electron transport, Phys. Rev. A 312932

[32] Pitchford L C, Alves L L, Bartschat K, Biagi S F, Bordage M C, Phelps A V, Ferreira C M, Hagelaar G J M, Morgan W L, Pancheshnyi S, Puech V, Stauffer A and Zatsarinny O 2013 Comparisons of sets of electron-neutral scattering cross sections and swarm parameters in noble gases: I. Argon, J. Phys. D: Appl. Phys. 46334001

[33] Dahl D A, Teich T A, Franck C M 2012 Obtaining precise electron swarm parameters from a pulsed Townsend setup, J. Phys. D: Appl. Phys. 45485201

[34] Chachereau A, Rabie M, Franck C M 2016 Electron swarm parameters of the hydrofluoroolefine HFO1234ze, Plasma Sources Sci. Technol. 25045005

[35] ETHZ database, www.lxcat.net.

[36] Yamaji M, Nakamura Y 2003 Measurements of electron transport coefficients in the $0.468 \%$ and $4.910 \% \mathrm{c}-\mathrm{C}_{4} \mathrm{~F}_{8} / \mathrm{Ar}$ mixtures and pure c- $\mathrm{C}_{4} \mathrm{~F}_{8}$, J. Phys. D: Appl. Phys. 36640644

[37] Long W H Jr., Bailey F W, and Garscadden A 1976 Electron drift velocities in molecular-gas-raregas mixtures, Phys. Rev. A. 13471 
[38] Petrovic Z Lj, Crompton R W and Haddad G N 1984 Model Calculations of Negative Differential Conductivity in Gases, Aust. J. Phys. 3723

[39] Vrhovac S B and Petrovic Z Lj 1996 Momentum transfer theory of nonconservative charged particle transport in mixtures of gases: General equations and negative differential conductivity, Phys. Rev. E 534012

[40] Aleksandrov N L 1988 Three-body electron attachment to a molecule, Usp. Fiz. Nauk 154 177-206

[41] Christophorou L G, Mathis R A, Hunter S R, and Carter J G 1988 Effect of temperature on the uniform field breakdown strength of electronegative gases, Journal of Applied Physics $\mathbf{6 3} 52$

[42] Hunter S R, Christophorou L G, McCorkle D L, Sauers I, Ellis H W and James D R, Anomalous electron attachment properties of perfluoropropylene (1-C3F6) and their effect on the breakdown strength of these gases, J. Phys. D: Appl. Phys. 16 573-580 